\title{
Temporal Transcription Profiling of Sweet Orange in Response to PthA4-Mediated Xanthomonas citri subsp. citri Infection
}

\author{
Yang Hu, Shuo Duan, Yunzeng Zhang, Deepak Shantharaj, Jeffrey B. Jones, and Nian Wang
}

First, fourth, and fifth authors: Department of Plant Pathology, University of Florida, Gainesville 32611; and second, third, and sixth authors: Citrus Research and Education Center, Department of Microbiology and Cell Science, University of Florida, 700 Experiment Station Road, Lake Alfred 33850.

Current address of Y. Hu: Institute of Genetics and Developmental Biology Chinese Academy of Sciences, Beijing, 100101. Accepted for publication 11 January 2016.

\begin{abstract}
Hu, Y., Duan, S., Zhang, Y., Shantharaj, D., Jones, J. B., and Wang, N. 2016. Temporal transcription profiling of sweet orange in response to PthA4-mediated Xanthomonas citri subsp. citri infection. Phytopathology 106:442-451.

Citrus canker, caused by Xanthomonas citri subsp. citri, is a devastating disease of most commercial citrus varieties. In our previous study, we analyzed the transcriptional response of 'Valencia' sweet orange to X. citri subsp. citri wild-type and pthA4 mutant infection at $48 \mathrm{~h}$ postinoculation (hpi). Using microarray analysis, two PthA4 targets, CsLOB1 and CSSWEET1, were identified. We have shown that PthA4 binds to the effector binding element (EBE) of $C s L O B 1$ and activates gene expression of this susceptibility gene. However, how PthA4 modulates host genes at different stages of infection remains to be determined. In this study, we compared the transcriptional profiles between citrus leaf tissue inoculated with Xcc306 and those inoculated with a pthA4-deletion mutant strain

genes involved in cell-wall degradation and modification, DNA packaging, G-protein, protein synthesis, sucrose metabolism, and cell division functions, while the downregulated genes were mainly enriched in photosynthesis, transport, secondary metabolism, cytochrome $\mathrm{P} 450$, and various plant defenseassociated mechanisms. To validate microarray results, gene expression of 26 genes representing genes associated with cell-wall-associated, immunity system, and carbohydrate metabolism was confirmed using quantitative reverse-transcription polymerase chain reaction. Expression patterns of these genes at 48 and $120 \mathrm{hpi}$ were consistent with the microarray results. We also identified putative EBE for PthA4 (EBEPthA4) in the promoter regions of multiple genes upregulated by PthA4, to which PthA4 might bind directly to control their gene expression. Our study provided a dynamic picture of citrus genes regulated by PthA4 during the $X$. citri subsp. citri infection of citrus leaves at different stages. This study will be useful in further understanding the virulence mechanism of $X$. citri subsp. citri and identifying potential targets of PthA4.
\end{abstract} (Xcc306 $\Delta p t h A 4)$ at 6, 48, and 120 hpi. At both 48 and 120 hpi, the PthA4mediated infection significantly upregulated expression of a variety of
Additional keyword: transcriptome.
Citrus is one of the most economically important and extensively grown fruit tree crops worldwide (Boriss 2015). Citrus canker, which was originally identified in Southeast Asia and now is widely distributed in most citrus-producing countries, including Brazil, the United States, and China, poses a significant threat to the citrus industry. Citrus canker has caused huge economic losses due to reduced fruit quality and productivity, eradication programs, and regulatory restrictions.

Citrus canker affects all commercial citrus species and is caused by two phylogenetically distinct species of Xanthomonas: Xanthomonas citri subsp. citri and X. fuscans subsp. aurantifolii (Schaad et al. 2006). X. citri subsp. citri is the major pathogen in areas where citrus canker is present. $X$. citri subsp. citri is composed of strains that have been designated as A, Aw, and A* pathotypes, each with different host ranges. $X$. fuscans subsp. aurantifolii is grouped into pathotypes B and C. X. citri subsp. citri uses the type III secretion (T3S) system (Büttner and Bonas 2010; Laia et al. 2009) to deliver type III effectors to modify plant defense, acquire nutrients, cause typical canker symptoms, and assist bacterial release from the lesion (Brunings and Gabriel 2003). X. citri subsp. citri strain A (Xcc-A) and strain Aw (Xcc-Aw) contain 29 and 30 T3S effectors,

Corresponding author: N. Wang; E-mail address: nianwang@ufl.edu

*The $e$-Xtra logo stands for "electronic extra" and indicates that four supplementary figures and five supplementary tables are published online.

http://dx.doi.org/10.1094/PHYTO-09-15-0201-R

(C) 2016 The American Phytopathological Society respectively (Escalon et al. 2013; Jalan et al. 2013), while $X$. fuscans subsp. aurantifolii strain B (Xfa-B) and strain C (Xfa-C) contain 27 and 26 T3S effectors, respectively (Moreira et al. 2010). Among all the type III effectors, PthA is a canker pathogenicity determinant and its homologs are present in all strains of the two Xanthomonas spp. that cause typical citrus canker disease (Cubero and Graham 2002; Swarup et al. 1992). Representative strains of the five different pathotypes that are responsible for citrus canker-Xcc-A, Xcc-A*, Xcc-Aw, Xfa-B, and Xfa-C—contain pthA homologs, which are designated $p t h A, p t h A^{*}, p t h A w, p t h B$, and $p t h C$, respectively, and are essential for pustule formation on citrus (Al-Saadi et al. 2007). Transient expression of $p t h A$ in host plant cells was sufficient to induce citrus canker symptoms that include hypertrophy, hyperplasia, and necrosis (Duan et al. 1999). PthA and its homologs are transcription activator-like (TAL) effectors and contain nearly identical repeats of 34 amino acids in their central portion, an N-terminal T3S and translocation signal, a leucine zipper, three nuclear localization signal sequences, and an acidic transcriptional activation domain in the $\mathrm{C}$ terminus (Al-Saadi et al. 2007; Brunings and Gabriel 2003; Lahaye and Bonas 2001). PthA and its homologs are able to enter the plant nucleus and presumably activate host gene expression (Brunings and Gabriel 2003). Interestingly, de Souza et al. (2012) have identified PthA4-interacting proteins, including DNA or RNA-binding factors implicated in chromatin remodeling and repair, gene regulation, and mRNA stabilization or modification, further supporting the model of PthA4 being a TAL effector. TAL effectors bind to plant DNA elements, which are designated as effector binding elements (EBE), within the promoter regions via a series of amino acid repeats in the 
central coding portion (Boch et al. 2009; Hann et al. 2010; Moscou and Bogdanove 2009). The code for the interaction specificity between TAL effectors and EBE was cracked, indicating that the 12 th and 13th repeat-variable diresidues determine the binding specificity of TAL and sequence of EBE (Boch et al. 2009; Moscou and Bogdanove 2009). Several TAL effector target prediction tools have been established for detecting the presence of EBE in gene promoters (Doyle et al. 2012; Grau et al. 2013; Pérez-Quintero et al. 2013).

Recently, we analyzed the transcriptional response of 'Valencia' sweet orange to $X$. citri subsp. citri wild-type (WT) and pthA4 mutant (MU) infection at 120 hpi. The microarray data helped us identify two PthA4 targets, CsLOB1 and CsSWEET1. We have shown that PthA4 binds to the EBE of $C s L O B 1$ and activates its gene expression. We demonstrated that $C S L O B 1$ is the major target of PthA4 and a citrus canker susceptibility gene (Hu et al. 2014). Zheng et al. (2014) also reported that $C s L O B$ of citrus is targeted by PthA4. CsLOB1 belongs to the lateral organ boundaries (LOB) domain family of transcription factor, which may modulate the downstream genes that contribute to the susceptibility. Multiple cell-wall-associated genes have been validated to be mediated by the expression of CsLOB1 (Hu et al. 2014). However, in the previous study, we only analyzed the transcriptional response of Valencia sweet orange to $X$. citri subsp. citri WT and pthA4 MU infection at 120 hpi. How PthA modulates host genes at different stages of infection remains to be determined. In addition, the overall transcriptional effect of PthA4 on citrus was not analyzed in our previous study (Hu et al. 2014).

Microarray analyses of the transcriptional response of citrus to Xanthomonas spp. infection have been conducted using the citrus GeneChip. Cernadas et al. (2008) surveyed the early molecular events leading to canker development by performing transcriptional analysis of sweet orange plants infected with $X$. citri subsp. citri strain 306 (Xcc306) and Xfa-C strains, which elicit canker disease and the hypersensitive response, respectively. They observed that genes with significant expression changes in leaves after being infected by Xcc306 were involved in defense, cell wall modification and degradation, hormone response, vesicle trafficking, transcriptional regulation, and cell division. Fu and colleagues (Fu and Liu 2013; Fu et al. 2012) conducted two studies to investigate the global gene transcriptional changes after $X$. citri subsp. citri infection, by comparing the canker-resistant 'Meiwa' kumquat and the cankerresistant transgenic sweet orange with canker-susceptible WT sweet orange. Khalaf et al. (2011) revealed that varieties of genes associated with oxidative burst, protein degradation, and photosynthesis were differentially expressed in kumquat following the challenge of $X$. citri subsp. citri. In addition, the global transcriptional responses of citrus were analyzed following infection with the nonhost bacterium $X$. campestris pv. vesicatoria (Daurelio et al. 2013).

TABLE 1. Comparison of gene expression of sweet orange in response to wild-type (WT) and pthA4 mutant (MU) of Xanthomonas citri subsp. citri via microarray (MA) and quantitative reverse-transcription polymerase chain reaction (PCR)

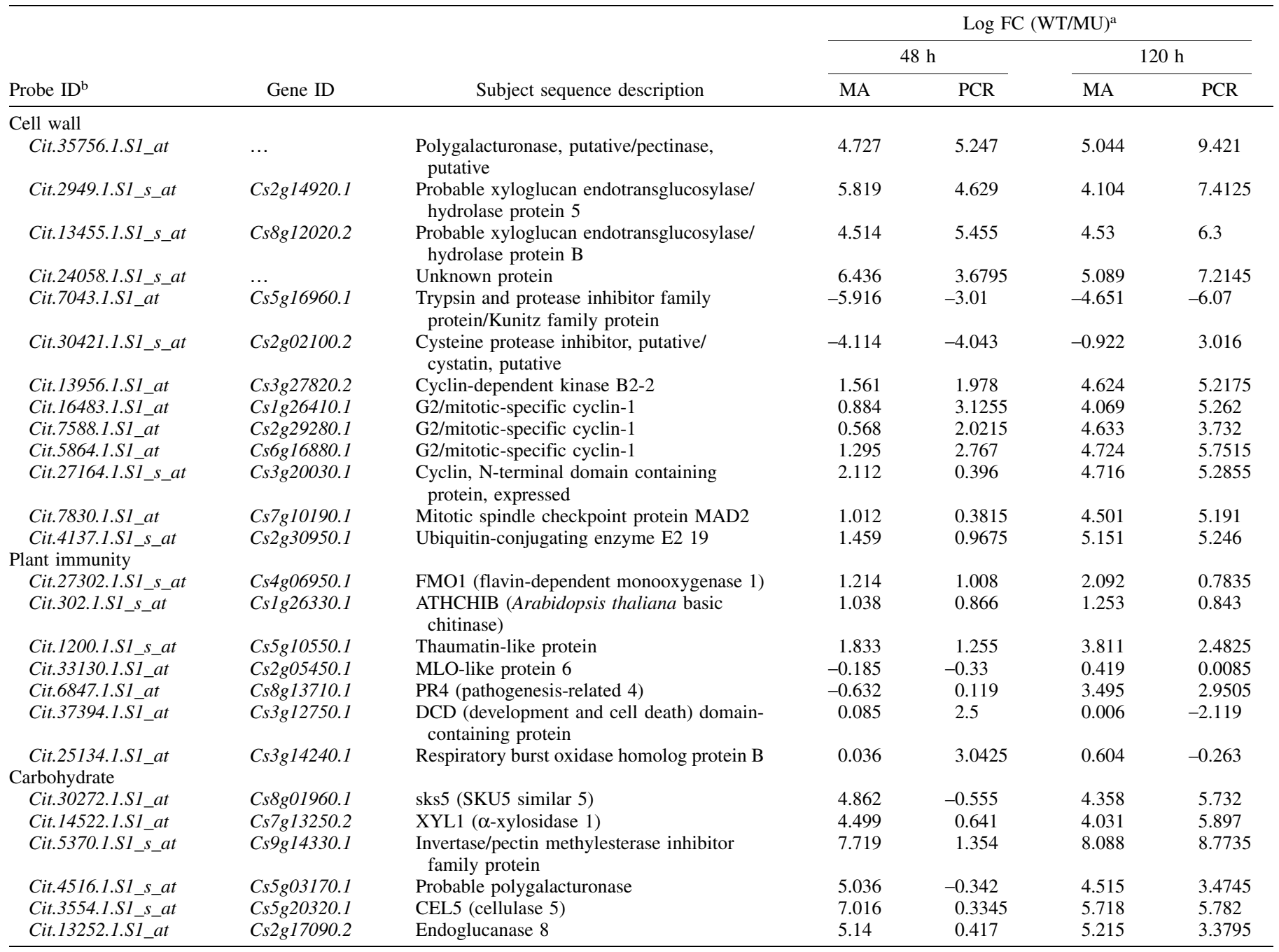

${ }^{a} \mathrm{FC}=$ fold change of sweet orange in response to WT and pthA4 MU of X. citri subsp. citri.

b Genes related to cell wall, plant immunity, or the carbohydrate metabolic process. 
Nevertheless, limited work has been done to examine temporal plant genome-wide transcriptional responses mediated by T3S effectors, which induce effector-triggered susceptibility or effectortriggered immunity. Truman et al. (2006) revealed that T3S effectors

TABLE 2. Citrus gene categories with significant expression change by the infection of wild-type Xcc306 (WT) relative to mutant Xcc306 $\Delta p t h A 4$ (MU) at 6,48 , and $120 \mathrm{~h}$ postinoculation (hpi)

\begin{tabular}{|c|c|c|}
\hline Functional categories & Probe number & $P$ value \\
\hline \multicolumn{3}{|l|}{6 hpi WT versus MU } \\
\hline Upregulated (NS) ${ }^{\mathrm{a}}$ & 29 & $\ldots$ \\
\hline Downregulated & 233 & $\ldots$ \\
\hline Auxin responsive & 2 & $1.5 \times 10^{-2}$ \\
\hline Acid and other phosphatases & 3 & $9.5 \times 10^{-3}$ \\
\hline \multicolumn{3}{|l|}{48 hpi WT versus MU } \\
\hline Upregulated & 727 & $\ldots$ \\
\hline Cell wall & 43 & $5.0 \times 10^{-6}$ \\
\hline Cell wall degradation & 11 & $3.9 \times 10^{-5}$ \\
\hline Cell wall modification & 15 & $1.7 \times 10^{-6}$ \\
\hline Secondary metabolism-phenylpropanoids & 3 & $8.0 \times 10^{-3}$ \\
\hline Hormone metabolism-brassinosteroid & 2 & $3.4 \times 10^{-2}$ \\
\hline$\beta-1,3$ Glucan hydrolases & 5 & $3.5 \times 10^{-2}$ \\
\hline bZIP transcription factor family & 4 & $4.3 \times 10^{-2}$ \\
\hline DNA synthesis/chromatin structure & 31 & $1.2 \times 10^{-4}$ \\
\hline Protein synthesis & 15 & $4.0 \times 10^{-3}$ \\
\hline Ribosomal protein synthesis & 14 & $9.1 \times 10^{-3}$ \\
\hline Signaling in sugar and nutrient & 2 & $4.0 \times 10^{-2}$ \\
\hline Downregulated & 584 & $\ldots$ \\
\hline Photosynthesis & 24 & $4.4 \times 10^{-4}$ \\
\hline Light reaction & 19 & $1.0 \times 10^{-3}$ \\
\hline Stress & 37 & $1.1 \times 10^{-8}$ \\
\hline Stress-biotic & 30 & $4.9 \times 10^{-10}$ \\
\hline Stress-biotic, pathogenesis-related proteins & 25 & $2.6 \times 10^{-11}$ \\
\hline Posttranslational modification in kinase & 3 & $3.8 \times 10^{-2}$ \\
\hline Signaling receptor kinases & 8 & $1.1 \times 10^{-2}$ \\
\hline Receptor kinases-DUF 26 & 3 & $8.6 \times 10^{-3}$ \\
\hline Development & 14 & $3.0 \times 10^{-2}$ \\
\hline \multicolumn{3}{|l|}{120 hpi WT versus MU } \\
\hline Upregulated & 913 & $\ldots$ \\
\hline Cell wall & 53 & $2.9 \times 10^{-3}$ \\
\hline Cell wall degradation & 16 & $1.4 \times 10^{-2}$ \\
\hline Cell wall modification & 16 & $3.1 \times 10^{-2}$ \\
\hline Glycolipid synthesis & 3 & $3.8 \times 10^{-2}$ \\
\hline FA synthesis & 2 & $2.5 \times 10^{-2}$ \\
\hline Auxin responsive & 5 & $1.9 \times 10^{-2}$ \\
\hline Redox regulation & 6 & $6.4 \times 10^{-3}$ \\
\hline Development & 23 & $3.7 \times 10^{-3}$ \\
\hline Transport & 26 & $5.5 \times 10^{-4}$ \\
\hline Sugar transporter & 3 & $2.0 \times 10^{-2}$ \\
\hline Metabolite transporter & 2 & $3.6 \times 10^{-2}$ \\
\hline Downregulated & 1,094 & $\ldots$ \\
\hline Photosynthesis & 73 & $5.8 \times 10^{-2}$ \\
\hline Light reaction & 56 & $1.7 \times 10^{-2}$ \\
\hline Cell wall & 31 & $2.9 \times 10^{-3}$ \\
\hline Cell wall AGPs proteins & 4 & $1.5 \times 10^{-2}$ \\
\hline Cell wall pectin methyl esterase & 3 & $1.5 \times 10^{-2}$ \\
\hline Lipid metabolism & 31 & $9.0 \times 10^{-3}$ \\
\hline FA synthesis & 11 & $2.5 \times 10^{-3}$ \\
\hline Lipid transfer proteins & 4 & $1.7 \times 10^{-2}$ \\
\hline Stress & 21 & $4.4 \times 10^{-2}$ \\
\hline Redox. glutaredoxins & 5 & $2.8 \times 10^{-2}$ \\
\hline Miscellaneous enzymes & 117 & $4.4 \times 10^{-4}$ \\
\hline Lipid transfer protein & 7 & $2.8 \times 10^{-2}$ \\
\hline GDSL-motif lipase & 17 & $3.0 \times 10^{-5}$ \\
\hline Nitrile lyases & 10 & $1.2 \times 10^{-2}$ \\
\hline RNA & 50 & $2.0 \times 10^{-4}$ \\
\hline Regulation of transcription & 46 & $2.3 \times 10^{-3}$ \\
\hline TCP transcription factor & 5 & $4.6 \times 10^{-2}$ \\
\hline AP2/ERF transcription factor & 4 & $4.7 \times 10^{-2}$ \\
\hline Aux/IAA family & 4 & $1.3 \times 10^{-2}$ \\
\hline Protein & 43 & $1.9 \times 10^{-2}$ \\
\hline Posttranslational modification & 9 & $3.8 \times 10^{-2}$ \\
\hline Minor CHO metabolism & 14 & $4.4 \times 10^{-2}$ \\
\hline Light signaling & 7 & $8.9 \times 10^{-3}$ \\
\hline Receptor kinase & 18 & $4.9 \times 10^{-2}$ \\
\hline
\end{tabular}

a NS = no significant category. suppressed the expression of genes in categories of leucine-rich repeat receptor-like kinase, primary carbon metabolism, aromatic biosynthesis, and phenylpropanoids and induced MYB, NAC, and AP2 transcription factor genes in Arabidopsis, by comparing the invasion of Pseudomonas syringae pv. tomato DC3000 with that of T3S effector delivery deficient MU strain DC3000 hrp-. AvrBs3 of $X$. campestris pv. vesicatoria was reported to induce auxininduced genes, $\alpha$-expansin gene, pectate lyase, and anthocyanidin rhamnosyl transferase genes in pepper (Marois et al. 2002). Balaji et al. (2007) observed that 139 genes and 1,294 genes had significant changes in transcript levels at $8 \mathrm{~h}$ and $12 \mathrm{~h}$ postinoculation (hpi), respectively, following inoculation of isogenic $X$. campestris pv. vesicatoria strains differing only in the $a v r X v 3$ gene.

In this study, we further analyzed how PthA4 modulates host genes at different stages of bacterial infection by investigating the transcriptional response of Valencia sweet orange to $X$. citri subsp. citri WT and pthA4 MU infection at 6, 48, and $120 \mathrm{hpi}$. We provided the overall transcriptional effect of PthA4 on citrus in this study. The microarray result has been validated using quantitative reversetranscription polymerase chain reaction (qRT-PCR). In addition, we searched the putative $\mathrm{EBE}_{\mathrm{PthA} 4}$ and target genes in the pool of genes upregulated by PthA4.

\section{MATERIALS AND METHODS}

Plant materials and bacterial strains. Valencia sweet orange (Citrus sinensis) plants were kept in a quarantine greenhouse facility at the Citrus Research and Education Center, Lake Alfred, FL. The temperature ranged between 25 and $30^{\circ} \mathrm{C}$ with a 12 -h photoperiod. Before inoculation, the plants were pruned to stimulate new leaves. The leaves chosen for infiltration were fully expanded, immature leaves, 14 to 21 days old. The plasmids and bacterial strains used in this study are list in Supplementary Table S1. Strains of Xanthomonas were grown at $28^{\circ} \mathrm{C}$ on nutrient agar (NA), Escherichia coli was grown at $37^{\circ} \mathrm{C}$ in lysogeny broth.

Microarray experiment and analyses. Xcc306 WT strain and Xcc306 $\Delta$ pthA4 MU were cultured on NA plates and used to inoculate Valencia sweet orange at the concentration of $5 \times 10^{8}$ $\mathrm{CFU} / \mathrm{ml}$ suspended in sterile tap water. The suspensions were infiltrated with a needle and syringe into the entire leaf, then kept in a growth chamber for the duration of the experiment. Leaves were harvested 6, 48, and 120 hpi for RNA isolation. We compared the global transcriptome profiles of citrus with the infections of the two near-isogenic strains using microarray analysis. To allow stringent statistical data analysis, three biological replicates were conducted and three leaves were pooled for each replicate per time point. RNA extraction was performed by using the RNeasy Plant Mini Kit (Qiagen, Valencia, CA). Microarray analysis was conducted using an Affymetrix array containing 30,171 probesets representing up to 33,879 citrus transcripts. Labeling, hybridization, washing, scanning, and data analysis were performed at the ICBR (Interdisciplinary Center for Biotechnology Research) facility at University of Florida in Gainesville. Statistical tests were performed using BioConductor statistical software, an open source software based on the $\mathrm{R}$ programming language (http://www.bioconductor.org/). A robust multichip analysis approach was used for normalizing the raw data. Differential expression analysis was carried out using a linear modeling approach and the empirical Bayes statistics implemented in the Limma package. Differentially expressed genes with an adjusted $P$ value (false discovery rate [FDR]) $\leq 0.05$ were considered to be differentially expressed genes at a statistically significant level. Differentially expressed genes were defined as genes with an expression fold change $\geq 3.0$ (|log fold change| of 1.58) in comparison with leaves inoculated with WT and MU strains, and that were statistically significant at an adjusted $P$ value $\leq$ 0.05 . The microarray data have been deposited in the National Center for Biotechnology Information's Gene Expression Omnibus (GEO) and are accessible through GEO accession number GSE52700 and 
GSE50741. We compared the differentially expressed genes at 6, 48, and 120 hpi to observe the dynamics of PthA4-mediated responses, and analyzed the citrus genes that changed in mRNA level in response to WT infection between the three time points. We further assigned the differentially expressed genes into functional categories according to their similarity to genes with known functions in plants using two distinct programs, MapMan software (Thimm et al. 2004; Usadel et al. 2005) and the web-based singular enrichment analysis (SEA) tool in the AgriGO program (Du et al. 2010).

qRT-PCR analyses. The RNA was subjected to DNase I treatment and first-strand cDNA synthesis by using the ProtoScript AMV First-Strand cDNA Synthesis Kit (NEB, Ipswich, MA). Two-step real-time PCR was performed using RealMasterMix SYBR Rox (5 PRIME, Gaithersburg, MD). The gene-specific primer sequences are listed in Supplementary Table S2. The elongation factor (EF) gene EFl $\alpha$ was used as endogenous control. The $2^{-\Delta \Delta \mathrm{Ct}}$ method was used for relative quantification (Livak and Schmittgen 2001).

Categorization of differentially expressed genes. For MapMan analysis, the microarray data of each comparison with log twofold change value and FDR value were loaded into the software with a filter of FDR $<0.05$. The pathways were visualized in the context of built-in Citrus AFFY mapping, and a Wilcoxon rank sum test implemented in MapMan was used to extract the item number in each BIN and return BIN whose gene members exhibited a

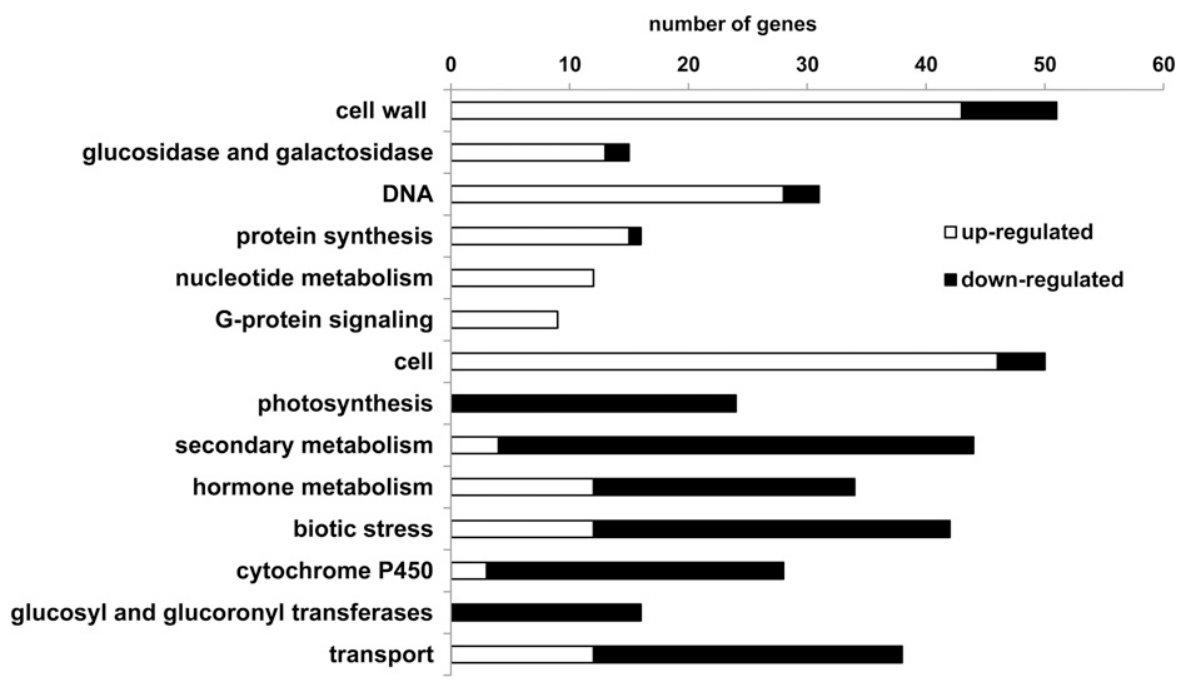

Fig. 1. Comparison of PthA4 upregulated and downregulated genes of citrus by wild-type versus mutant Xanthomonas citri subsp. citri strain infection at $48 \mathrm{~h}$ postinoculation based on MapMan analysis. Bar chart showing the categories with upregulated genes (white bars) and downregulated (black bars).

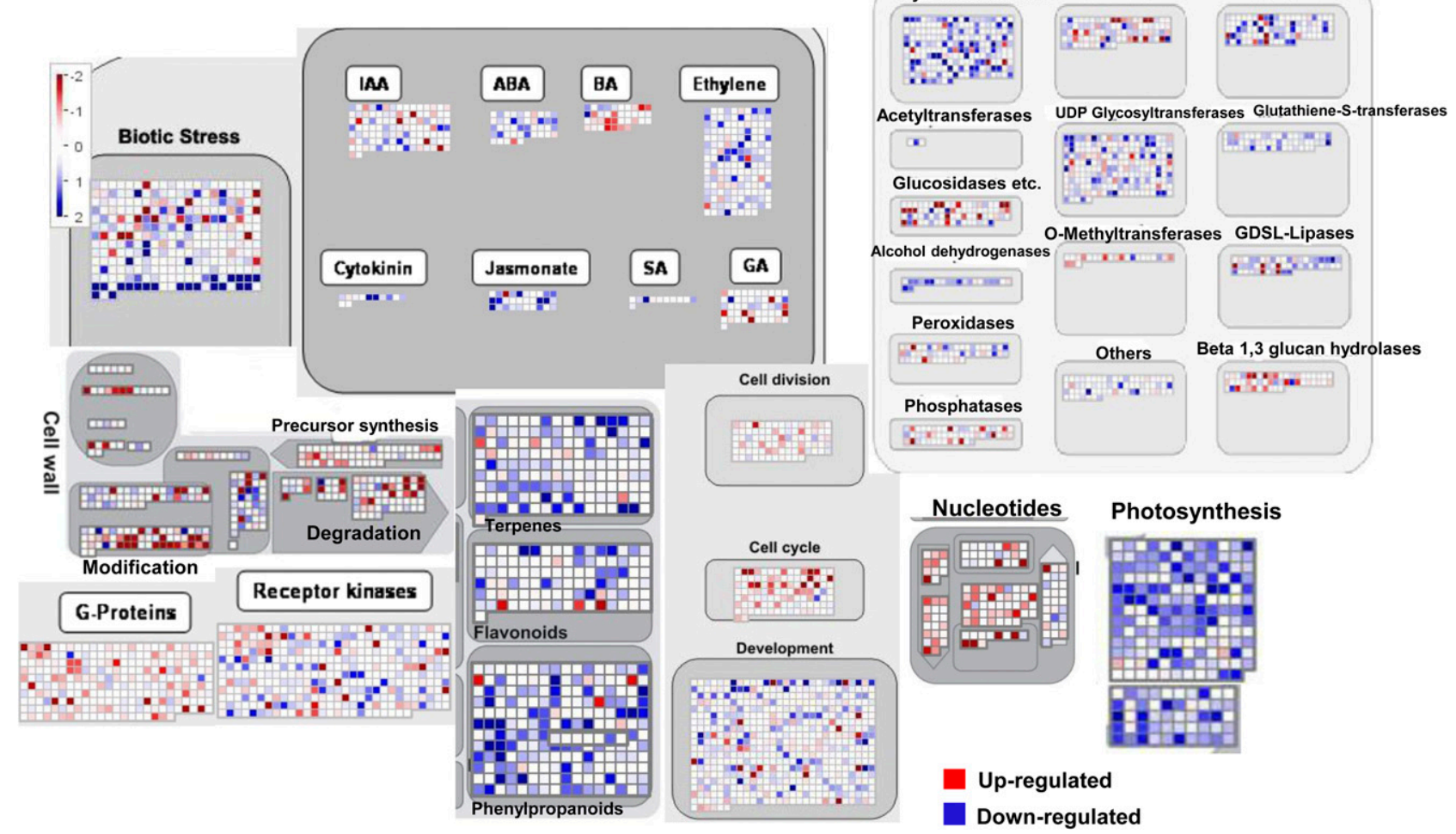

Fig. 2. Visualization of PthA4 upregulated genes and downregulated citrus genes in different categories by wild-type versus mutant Xanthomonas citri subsp. citri strain infection at $48 \mathrm{~h}$ postinoculation using MapMan software. The scale with $\log _{2}$ fold change is shown. 
significant difference in expression. To analyze gene ontology (GO) term enrichment of differentially expressed genes, SEA was performed online through the agriGO program, a GO analysis tool kit for the agricultural community (http://bioinfo.cau.edu.cn/ agriGO). Briefly, the differentially expressed gene probe identification numbers were first uploaded into agriGO; then, the Citrus Affymetrix Genome Array was selected as the reference, statistical $P$ values were calculated using the Fisher method, and multipletest adjustment was performed using the Yekutieli (FDR under dependency) method. The Venn diagrams were generated using an online program, Draw Venn Diagram (http://bioinformatics. psb.ugent.be/webtools/Venn/).

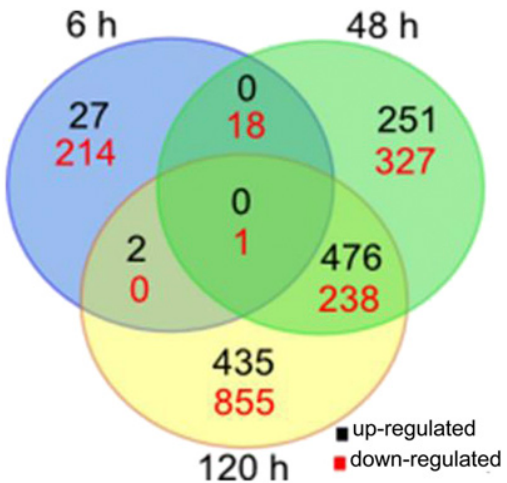

Fig. 3. Venn diagram showing the number of upregulated (black font) or downregulated (red font) genes modulated at 6,48 , and $120 \mathrm{~h}$ postinoculation following wild-type strain Xcc306 inoculation relative to mutant strain Xcc306 $\Delta p t h A 4$ inoculation. The genes with fold change no less than 3 and adjusted $P$ value $\leq 0.05$ were considered up- or downregulated.

\section{RESULTS}

Validation of microarray data using qRT-PCR. To validate the microarray results, 26 citrus genes were tested for their expression at 48 and 120 hpi using qRT-PCR. The qRT-PCR results suggested that the expression patterns of most genes were consistent with the microarray results (Table 1).

Characterization of differentially expressed genes following inoculation of WT relative to MU strain at 6, 48, and $120 \mathrm{hpi}$. We employed the MapMan Wilcoxon Rank Sum Test to classify the differentially expressed genes and calculate the significance based on whether the probability that the differentially expressed genes assigned to a BIN or sub-BIN (function category) were statistically different from all other BIN or sub-BIN $(P$ value $<0.05)$. At 6 hpi, inoculation of WT in comparison with inoculation with MU strains resulted in 29 genes being induced and 233 citrus genes being suppressed. No category showed a significant difference for the upregulated (WT or MU) genes, whereas only two categories showed significant differences for the downregulated genes (Table 2). We found that, at this time point, the WT strain containing pthA4 downregulated a high percentage of genes sorted into the categories of transport, biotic stress, signaling (primarily receptor kinase), miscellaneous enzymes, RNA regulator, and secondary metabolism compared with MU strain Xcc306 $\Delta p t h A 4$ (Supplementary Fig. S1).

At 48 hpi, 1,311 differentially expressed genes were identified, which accounted for $4.35 \%$ of the total transcripts in the citrus GeneChip. Among them, 727 genes were upregulated and 584 genes were downregulated by WT infection compared with MU strain infection. According to the MapMan Wilcoxon Rank Sum Test, the main significantly upregulated categories were related to cell wall degradation and modification, DNA synthesis or chromatin structure, and ribosomal protein synthesis; while the processes related to plant defense response, photosynthesis, development,

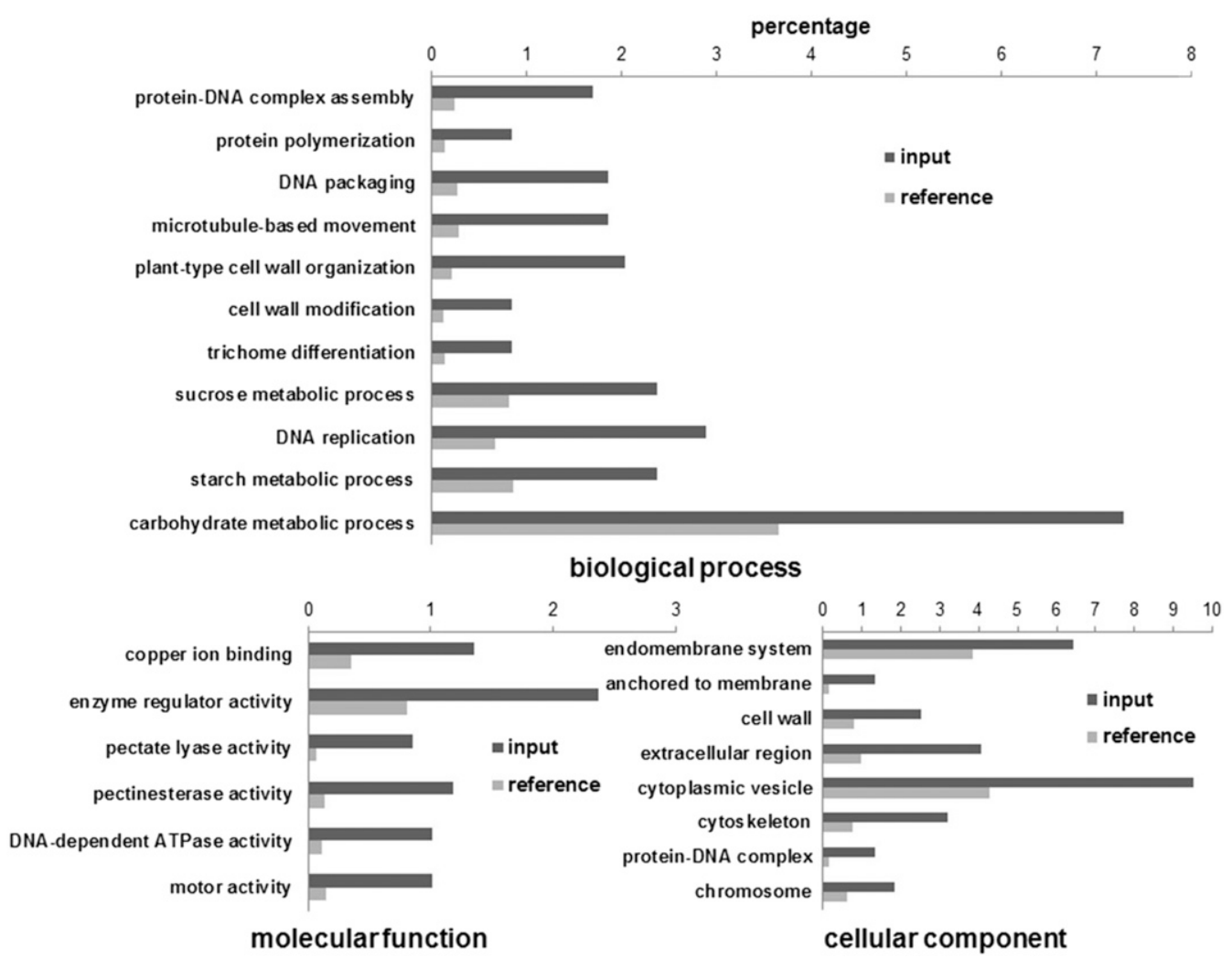

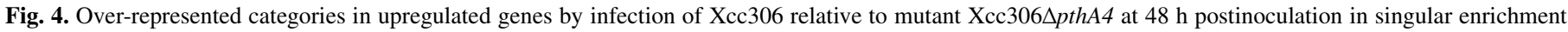

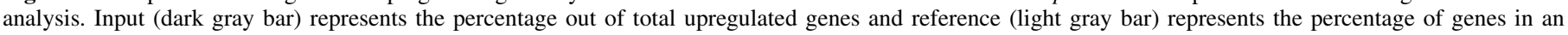

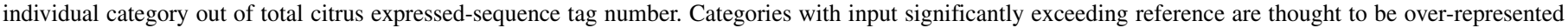

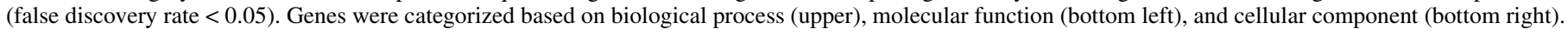


stress-related pathogenesis-related (PR) proteins, and receptor kinase signaling were the significantly downregulated categories (Table 2). Furthermore, we also examined the proportions of each annotated category. The categories of cell wall, cell (cell cycle and cell division), DNA, signaling, and transcription factor contained mostly upregulated genes (Supplementary Fig. S2), while the categories of miscellaneous enzyme families, secondary metabolism, biotic stress, photosynthesis, and transport contained the highest percentage of downregulated genes. When comparing the up- and downregulated genes in different categories, the categories of photosynthesis, secondary metabolism, hormone metabolism, biotic stress, cytochrome P450, transport, glucosyl, and glucoronyl transferase, which were enriched for downregulated genes, contained only limited numbers of upregulated items, while categories associated with cell wall, glucosidase and galactosidase, DNA, protein synthesis, nucleotide metabolism, G-protein signaling, and cell (cell cycle and cell division) contained a large number of upregulated genes and only a few downregulated genes (Fig. 1). We also displayed the differentially expressed genes and the corresponding categories in a MapMan visualized pathway diagram (Fig. 2), which showed the same affiliations as in Figure 1. However, the functions of a large number of differentially expressed genes were unassigned (42\% for upregulated and $37 \%$ for downregulated genes), which shared no reliable homology to genes deposited in public databases and were without known functions.

At $120 \mathrm{hpi}, 913$ and 1,094 citrus genes were up- and downregulated, respectively, after comparing WT infection with MU strain infection. A large number of functional categories exhibited significant expression changes, the pattern was similar with that at
48 hpi (Table 2; Supplementary Fig. S3) in MapMan analysis. The Mercator analysis showed that cell wall, cell (cell cycle and cell division), and DNA categories contained the highest proportion of upregulated genes (Supplementary Fig. S4A), while the proportions of photosynthesis and secondary metabolism categories were high in the downregulated genes (Supplementary Fig. S4B).

The overlapping differentially expressed genes at the three time points were compared by Venn diagram analysis. No gene was found to be upregulated by PthA4 at all three time points (Fig. 3). Only one gene, Cit.57.1.S1_x_at, which encodes a protease inhibitor protein, was identified to be downregulated at all three time points. A dramatic difference was observed for the transcriptional profiles at 48 and $120 \mathrm{hpi}$, despite the overlapping genes.

GO annotation of differentially expressed genes in citrus following inoculation by WT compared with MU strain at 6, 48, and 120 hpi. In AgriGO-SEA interpretation, the enrichment or over-representation of a category was assessed with a significantly (FDR $<0.05)$ higher percentage in total differentially expressed genes (input in Figures 4 and 5) than its overall percentage in the total expressed sequence tag (reference in Figures 4 and 5). At 6 hpi, the downregulated genes were enriched in the categories of innate immune response, oxidoreductase activity, carbohydrate binding, carboxylic acid biosynthesis, and ubiquitin ligase (Supplementary Table S3).

At $48 \mathrm{hpi}$, the over-represented categories of upregulated genes included DNA (protein-DNA complex assembly, DNA packaging, and DNA replication), cell wall (cell wall organization and modification), metabolism (carbohydrate, sucrose, and starch

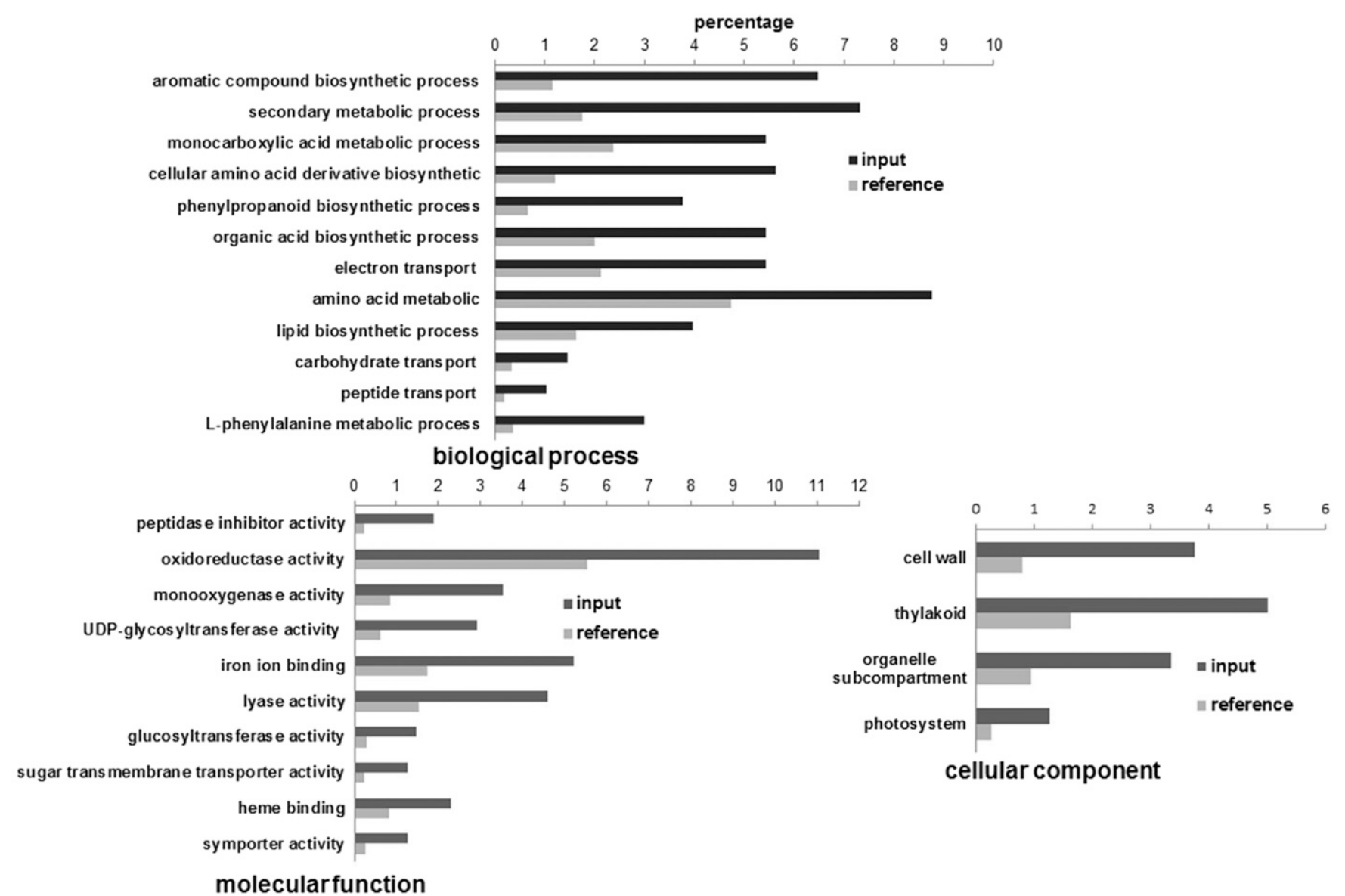

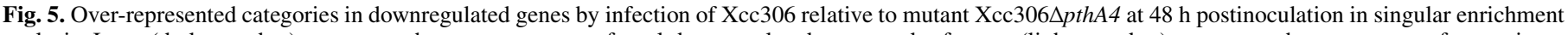

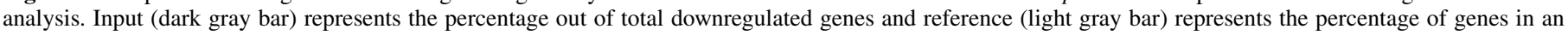

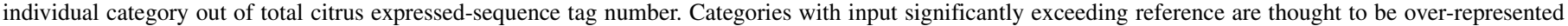

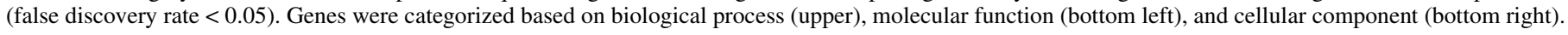


metabolic process), microtubule-based movement, protein polymerization, and trichome differentiation based on biological processes. The upregulated genes were also enriched in pectate lyase activity, pectinesterase activity, DNA-dependent ATPase activity, motor activity, copper ion binding, and enzyme regulator activity based on molecular function; and enriched in cell wall, endomembrane system, cytoplasmic vesicle, cytoskeleton, extracellular region, and protein-DNA complex based on cellular component (Fig. 4). For the downregulated genes, with regard to biological process, they were primarily enriched in phenylpropanoids, Lphenylalanine, monocarboxylic acid, amino acid, and lipid metabolism processes; and electron, peptide, and carbohydrate transport. In molecular function, the over-represented categories of downregulated genes were catalytic activity, transport, enzyme inhibitor, and ion and heme binding, while they were also enriched in cell wall, photosystem, thylakoid, and organelle subcompartment based on cellular component (Fig. 5).

TABLE 3. Categories with significant change in expression $(P$ value $<0.05)$ and differentially expressed probe set numbers through the comparisons of different times after infiltration of wild-type Xcc306 generated by MapMan software

\begin{tabular}{|c|c|c|}
\hline Function categories $^{a}$ & Probe number & $P$ value \\
\hline \multicolumn{3}{|l|}{48 versus 6 hpi } \\
\hline Upregulated & 1,147 & $\ldots$ \\
\hline Cell wall & 38 & $7.5 \times 10^{-10}$ \\
\hline Cell wall degradation & 13 & $1.5 \times 10^{-4}$ \\
\hline Cell wall modification & 16 & $3.1 \times 10^{-8}$ \\
\hline Stress & 75 & $1.8 \times 10^{-2}$ \\
\hline Biotic stress & 32 & $1.4 \times 10^{-2}$ \\
\hline Heat stress & 33 & $4.3 \times 10^{-2}$ \\
\hline Nitrile lyases & 8 & $5.2 \times 10^{-3}$ \\
\hline MYB-related transcription factor & 6 & $1.2 \times 10^{-2}$ \\
\hline $\mathrm{C} 2 \mathrm{C} 2(\mathrm{Zn})$-like zinc figure family & 5 & $3.4 \times 10^{-2}$ \\
\hline DNA synthesis & 28 & $2.9 \times 10^{-5}$ \\
\hline Ribosomal protein synthesis & 15 & $4.1 \times 10^{-2}$ \\
\hline Signaling & 59 & $3.6 \times 10^{-3}$ \\
\hline G-protein signaling & 11 & $1.2 \times 10^{-2}$ \\
\hline Transport & 51 & $1.7 \times 10^{-3}$ \\
\hline Downregulated & 1,119 & $\ldots$ \\
\hline Cell wall modification & 4 & $1.5 \times 10^{-2}$ \\
\hline Lipid transfer proteins & 4 & $4.5 \times 10^{-2}$ \\
\hline Lysophospholipases & 6 & $1.2 \times 10^{-2}$ \\
\hline Secondary metabolism-isoprenoids & 19 & $5.0 \times 10^{-2}$ \\
\hline Secondary metabolism-chalcones & 6 & $1.4 \times 10^{-2}$ \\
\hline Thiamine metabolism & 7 & $2.1 \times 10^{-2}$ \\
\hline Stress & 53 & $1.2 \times 10^{-3}$ \\
\hline Biotic stress & 32 & $7.5 \times 10^{-3}$ \\
\hline Pathogenesis-related protein & 23 & $1.4 \times 10^{-3}$ \\
\hline Proteinase inhibitors & 17 & $5.8 \times 10^{-4}$ \\
\hline Peroxidases & 10 & $3.7 \times 10^{-3}$ \\
\hline WRKY domain transcription factor family & 5 & $4.6 \times 10^{-3}$ \\
\hline RNA binding & 6 & $1.3 \times 10^{-3}$ \\
\hline Light signaling & 3 & $5.3 \times 10^{-3}$ \\
\hline \multicolumn{3}{|l|}{120 versus $48 \mathrm{hpi}$} \\
\hline Upregulated & 468 & $\ldots$ \\
\hline Cell & 27 & $1.9 \times 10^{-2}$ \\
\hline Cell cycle & 9 & $1.2 \times 10^{-2}$ \\
\hline Development & 17 & $1.3 \times 10^{-2}$ \\
\hline Late embryogenesis abundant & 3 & $1.3 \times 10^{-2}$ \\
\hline Downregulated & 552 & $\ldots$ \\
\hline Cell wall & 24 & $1.6 \times 10^{-2}$ \\
\hline Cell wall AGPs protein & 4 & $3.8 \times 10^{-3}$ \\
\hline Cell wall modification & 5 & $1.4 \times 10^{-3}$ \\
\hline Cell wall pectin methyl esterase & 3 & $1.7 \times 10^{-3}$ \\
\hline Lipid metabolism & 18 & $5.3 \times 10^{-4}$ \\
\hline FA synthesis & 9 & $2.7 \times 10^{-3}$ \\
\hline Biotic stress & 10 & $5.7 \times 10^{-3}$ \\
\hline Oxidases & 5 & $3.9 \times 10^{-2}$ \\
\hline Cell & 5 & $1.4 \times 10^{-2}$ \\
\hline Calcium transport & 3 & $4.5 \times 10^{-2}$ \\
\hline
\end{tabular}

a Abbreviation: hpi $=$ hours postinoculation.
Most of the differentially expressed genes at 48 and $120 \mathrm{hpi}$ had similar distribution patterns in AgriGO-SEA categorization. Moreover, oxidoreductase activity and lyase activity categories overrepresented the downregulated genes at all three time points.

Reprogramming of citrus gene expressions at different time points after $X$. citri subsp. citri inoculations. We compared the genome-wide expressions in citrus at 6, 48, or $120 \mathrm{hpi}$ following the infection by WT Xcc306, given the diversity of the differentially expressed genes in different time points. Xcc306 induced 1,147 and repressed 1,119 citrus genes at 48 hpi when compared with 6 hpi. Based on MapMan Wilcoxon Rank Sum analysis, the significantly upregulated categories included cell wall degradation and modification, heat stress, nitrile lyase, MYB transcription factors, DNA synthesis, ribosomal protein synthesis, signaling, G-protein, and transport; and the significantly downregulated categories included cell wall modification, lipid transfer proteins, isoprenoid metabolism, thiamine metabolism, PR protein, peroxidases, WRKY transcription factor family, RNA binding, and light signaling (Table 3 ). We also contrastingly and visually checked the differentially expressed genes in a MapMan Pathway diagram, which revealed that categories of cytochrome $\mathrm{P} 450$, terpenes, flavonoids, phenylproanoids, peroxidase, ethylene, and jasmonic acid contained remarkably more downregulated genes than upregulated genes, while classes of calcium, G-protein, cell wall, cell cycle, cell division, and auxin were enriched with more upregulated genes. Furthermore, we also performed an AgriGO-SEA test to interpret this time-based comparison (Supplementary Table S4). It illustrated that most of the differentially expressed gene-enriched categories were consistent with that in the comparison of WT versus MU strain at 48 hpi (Tables 2 and 3 ).

In addition, we conducted a comparative analysis between 48 and $120 \mathrm{hpi}$ following the WT infection. The number of differentially expressed genes in respect to this comparison was less than that of the 48 versus 6 hpi comparison (Table 3), and the significantly upregulated categories were mainly related to development. Based on the AgriGO-SEA study, the upregulated genes were enriched in categories of chitin catabolic process, starch and sucrose metabolic, cellular nitrogen compound metabolic, microtubule-base movement, mitosis, response to oxidative stress, cell cycle, cell division, peroxidase activity, chitinase activity, peptidase inhibitor activity, and heme binding, while the main, significantly downregulated categories included glucan metabolic process, lipid and peptide transport, response to auxin stimulus, developmental growth, monooxygenase activity, and carboxylesterase activity.

Candidate target genes that contain a potential EBE PthA4 $_{4}$ box in promoter region. In terms of the gene activation ability and DNA-binding specificity of PthA4, the potential EBE box from promoters of the PthA4-induced genes at three time points were searched. For this purpose, the upstream 1,000 bp before the $5^{\prime}$ untranslated region of these induced genes was extracted from the published sweet orange genome annotation (Xu et al. 2013) using a custom script and three distinct programs: Target Finder (Moscou and Bogdanove 2009), TALgetter (Grau et al. 2013), and TALVEZ (Pérez-Quintero et al. 2013) were employed to identify the EBE box. The optimized sequence of $\mathrm{EBE}_{\mathrm{PthA} 4}$ is supposed to be TATAAACCTCTTTTACCTT, and only the potential EBE starting with a $\mathrm{T}$ that precedes the first repeat were taken into consideration. As expected, at 48 and $120 \mathrm{hpi}$, the gene represented by Cit.37210.1.S1_at, which encodes CsLOB1, ranked number 1 in all three programs. At 48 hpi, 15 genes contain putative $\mathrm{EBE}_{\mathrm{PthA} 4}$, whereas 9 genes contain putative $\mathrm{EBE}_{\mathrm{PthA} 4}$ at $120 \mathrm{hpi}$. Four common genes were predicted to contain $\mathrm{EBE}_{\mathrm{PthA} 4}$ at 48 and $120 \mathrm{hpi}$ (i.e., Cit.37210.1. S1_at, Cit.5726.1.S1_at, Cit.30096.1.S1_at, and Cit.15320.1.S1_at). No potential EBE $\mathrm{EthA}_{4}$ was detected for the upregulated genes at $6 \mathrm{hpi}$ (Supplementary Table S5). Target Finder and TALgetter retrieved a similar gene pattern, whereas some of the target genes predicted by TALVEZ were different (Table 4). 


\section{DISCUSSION}

In this study, we used microarray analysis to scrutinize the reprograming of the transcription profiles in sweet orange following PthA4-dependent bacterial infection. Our study provided a dynamic picture of citrus genes regulated by PthA 4 during the $X$. citri subsp. citri infection of citrus leaves at different stages. This study will be useful in further understanding the virulence mechanism of $X$. citri subsp. citri and identifying potential targets of PthA4.

In Xcc306, PthA4 is the only TAL effector that is required and sufficient to reproduce typical citrus canker (Al-Saadi et al. 2007; Brunings and Gabriel 2003); therefore, how it exerts its functions inside plant tissues is critical for disease development and bacterial growth in planta. As a typical TAL effector, PthA4 presumably plays important roles in activating gene transcription, suppressing the plant defense system, and promoting plant vulnerabilities, which are supported by our microarray analysis of plant response to $X$. citri subsp. citri infection with or without PthA4. We revealed that, at $6 \mathrm{hpi}$, PthA4 downregulated expression of genes involved in the plant innate immunity. Suppression of plant defense is important for bacterial pathogens to colonize the intercellular spaces (Dangl et al. 2013). At the later stages (48 and $120 \mathrm{hpi}$ ), the presence of PthA4 was necessary to induce expression of genes involved in various processes and functions (e.g., susceptibility and release of bacterial cells) and, meanwhile, inhibited expression of genes associated with plant defense response and plant development. Marois et al. (2002) studied host genes induced by AvrBs3, a TAL effector present in $X$. campestris pv. vesicatoria, by performing a cDNA-amplified fragment length polymorphism analysis and identified 13 genes which mainly include auxin-induced and expansinlike genes. The host genes induced by AvrBs3 are suggested to be involved in hypertrophy development. Similarly, we also identified auxin-induced and expansin-like genes induced by PthA4, which suggests that both AvrBs3 and PthA are necessary for hypertrophy development. Two TAL effectors of $X$. oryzae pv. oryzae (i.e., PthXo1 and AvrXa7) activate sugar transporter genes SWEET11 and SWEET14 to promote sugar transport in the host plants to supply some of the nutritional needs of the bacterial pathogen (Antony et al. 2010; Chen et al. 2010; Yang et al. 2006). PthA4 upregulated genes in the signaling in sugar and nutrient category at $48 \mathrm{hpi}$ and in the sugar transporter category at $120 \mathrm{hpi}$, which suggests that PthA4 might have similar functions in promoting sugar transport for the nutritional needs of the pathogen (Table 2).

Furthermore, at 48 and $120 \mathrm{hpi}$, PthA4 was shown to be required for repressing genes in several categories that were known to play positive roles in plant defense. Plant cytochrome $\mathrm{P} 450$, which is a group of heme-containing monooxygenases, has been reported to be associated with the synthesis of plant defense compounds and defense against microbial pathogens (Fu et al. 2012; Hwang and Hwang 2010; Khalaf et al. 2007). UDP-glycosyl transferases, which catalyze the transfer of nucleotide-diphosphate-activated sugars to secondary metabolites, play positive roles in plant defense against pathogens (Langlois-Meurinne et al. 2005; Vogt and Jones 2000). Plant defense components which are defined as the secondary metabolism, including PR proteins, phenylpropanoids, terpenes, and flavonoids, prevent pathogen invasion and are generally considered to be indicators for defense responses to biotic stimuli ( $\mathrm{Fu}$ and Dong 2013; Sels et al. 2008). T3S effectors have been reported to repress plant defense by targeting key modules of plant immune signaling pathways such as immune receptor complexes and mitogen-activated protein kinase cascades either acting as

TABLE 4. Putative targets of PthA4 deduced from the upregulated genes at $48 \mathrm{~h}$ postinoculation predicted with three different programs

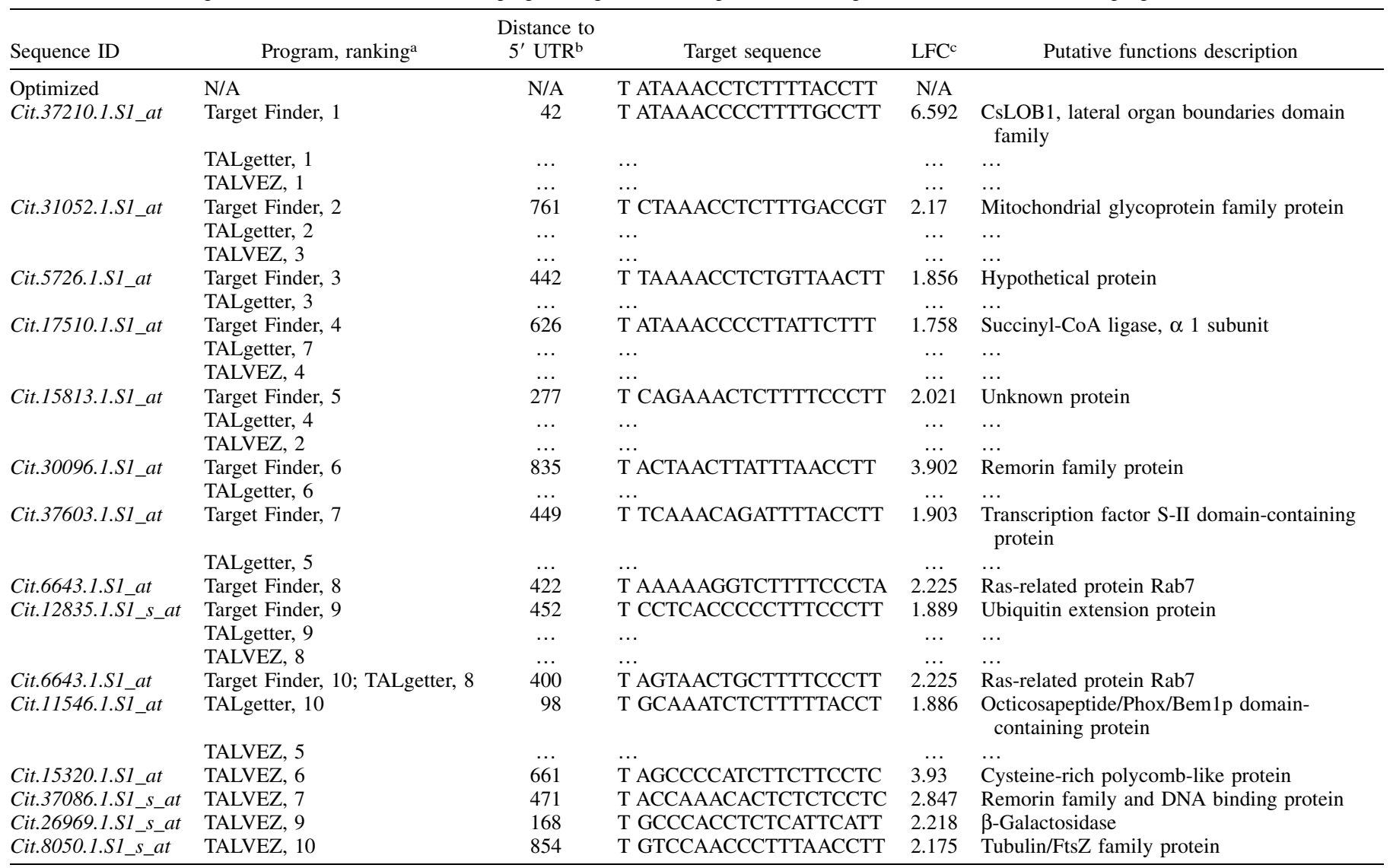

${ }^{\text {a }}$ N/A = not applicable.

${ }^{\mathrm{b}} \mathrm{UTR}=$ untranslated region.

${ }^{c} \mathrm{LFC}=\log _{2}$ fold change. 
enzymes (e.g., acetyltransferase, ADP-ribosyltransferease, cysteine protease, E3 ligase, protein tyrosine phosphatase, phosphothreonine lyase, and SUMO protease) or by physical association and interference (Axtell and Staskawicz 2003; Espinosa and Alfano 2004; Fu et al. 2007; Hotson et al. 2003; Janjusevic et al. 2006; Kim et al. 2009; Li et al. 2007; Shao et al. 2003; Tasset et al. 2010). How PthA4 exerts its effect on plant defense remains to be investigated.

As a typical TAL effector, PthA4 presumably targets host genes by binding to the EBE directly (Hu et al. 2014; Li et al. 2014). The known TAL effector target genes in planta, without exception, were highly induced by the corresponding TAL effectors (Antony et al. 2010; Gu et al. 2005; Kay et al. 2007; Yang et al. 2006; Yu et al. 2011). Interestingly, AvrBs3, another TAL effector of PthA/AvrBs3 family, has been shown to bind to a conserved element in the promoter of upa20, a master regulator of cell size, via its central repeat region and induces gene expression through its activation domain (Kay et al. 2007). Recently, we have identified two targets of PthA4 (i.e., CsLOB1 and CsSWEET1) that contain $\mathrm{EBE}_{\mathrm{PthA} 4}$ and are highly induced by PthA4. We demonstrated that CsLOB1 is the major target of PthA4 and a citrus canker susceptibility gene (Hu et al. 2014). Interestingly, we have identified multiple genes upregulated by PthA4 in addition to CsLOB1 containing sequences similar to $\mathrm{EBE}_{\mathrm{PthA} 4}$ in their promoter regions, although with low identity (Table 4). Whether PthA4 could directly interact with the promoters of those candidate genes and whether they are involved in modulating expression of plant defense-related genes need further elucidation.

Interestingly, dramatic transcriptional differences were observed for citrus to PthA4 at 6, 48, and 120 hpi of X. citri subsp. citri infection. One potential explanation for the differential expression of citrus to PthA4 at different time points is that $X$. citri subsp. citri may use PthA4 to regulate different sets of host genes at different infection stages (e.g., in early and late infection stages). Alternatively, this could be a cascade of events involving indirect regulation by PthA4 based on earlier events where PthA4 is critical. The fewer genes regulated at 6 hpi compared with 48 and 120 hpi indicate the time needed for $X$. citri subsp. citri to translocate PthA4 into the plant nucleus and, consequently, result in induction of citrus genes. PthA4 activated various genes involved in cell division, which is associated with hypertrophy and hyperplasia at 48 and 120 but not at 6 hpi. Hypertrophy and hyperplasia have been suggested to play important roles in bacterial growth and ultimate release from citrus canker lesions for further transmission (Brunings and Gabriel 2003; Yan and Wang 2012). Additionally, PthA4 upregulated many genes involved in cell wall modification at 48 or $120 \mathrm{hpi}$ (Table 2). This expression pattern is consistent with pustule symptoms of citrus canker. The cell wall modification-associated genes (e.g., cell wall disassembly enzyme encoding genes) are involved in the increase in plant vulnerability (Cantu et al. 2008), which further benefits $X$. citri subsp. citri in planta. Intriguingly, the categories of DNA replication, synthesis, and packaging, which are involved in protein-DNA assembly, were significantly induced at 48 and $120 \mathrm{hpi}$. This is probably due to the fact that PthA4 requires the assistance of a protein-DNA interaction complex to activate the target genes.

Collectively, by dissecting the compendium of citrus host transcripts and their dynamics affected by PthA4-depentdent Xcc306 infection, we can gain insight into the chronology of molecular events in citrus susceptibility to Xcc306 and identify the most critical elements in citrus for disease initiation and development that are largely unknown. Our study indicated that $X$. citri subsp. citri employs PthA4 to regulate a suite of host genes to benefit $X$. citri subsp. citri. Furthermore, this study allows us to exploit and identify major genes that are potentially responsible for citrus canker disease development, which could be used in molecular breeding to improve plant resistance to citrus canker. This data could provide useful information to explore the mechanisms of plant disease development mediated by other TAL effectors.

\section{ACKNOWLEDGMENTS}

This work was supported by the United States Department of Agriculture National Institute of Food and Agriculture Special Citrus Canker Grant Project 94430 and National Research Initiative Competitive Grants Program Grant 2012-67013-19383. We thank L. Malyak for her critical reading of this manuscript.

\section{LITERATURE CITED}

Al-Saadi, A., Reddy, J. D., Duan, Y. P., Brunings, A. M., Yuan, Q., and Gabriel, D. W. 2007. All five host-range variants of Xanthomonas citri carry one pthA homolog with 17.5 repeats that determines pathogenicity on citrus, but none determine host-range variation. Mol. Plant-Microbe Interact. 20:934-943

Antony, G., Zhou, J., Huang, S., Li, T., Liu, B., White, F., and Yang, B. 2010. Rice $x a 13$ recessive resistance to bacterial blight is defeated by induction of the disease susceptibility gene $O s-11 N 3$. Plant Cell 22:3864-3876.

Axtell, M. J., and Staskawicz, B. J. 2003. Initiation of RPS2-specified disease resistance in Arabidopsis is coupled to the AvrRpt2-directed elimination of RIN4. Cell 112:369-377.

Balaji, V., Gibly, A., Debbie, P., and Sessa, G. 2007. Transcriptional analysis of the tomato resistance response triggered by recognition of the Xanthomonas type III effector AvrXv3. Funct. Integr. Genomics 7:305-316.

Boch, J., Scholze, H., Schornack, S., Landgraf, A., Hahn, S., Kay, S., Lahaye, T., Nickstadt, A., and Bonas, U. 2009. Breaking the code of DNA binding specificity of TAL-type III effectors. Science 326:1509-1512.

Boriss, H. 2015. Commodity Profile: Citrus. http://www.agmrc.org/commoditiesproducts/fruits/citrus2/citrus-profile/

Brunings, A. M., and Gabriel, D. W. 2003. Xanthomonas citri: Breaking the surface. Mol. Plant Pathol. 4:141-157.

Büttner, D., and Bonas, U. 2010. Regulation and secretion of Xanthomonas virulence factors. FEMS Microbiol. Rev. 34:107-133.

Cantu, D., Vicente, A. R., Labavitch, J. M., Bennett, A. B., and Powell, A. L. 2008. Strangers in the matrix: Plant cell walls and pathogen susceptibility. Trends Plant Sci. 13:610-617.

Cernadas, R. A., Camillo, L. R., and Benedetti, C. E. 2008. Transcriptional analysis of the sweet orange interaction with the citrus canker pathogens Xanthomonas axonopodis pv. citri and Xanthomonas axonopodis pv. aurantifolii. Mol. Plant Pathol. 9:609-631.

Chen, L. Q., Hou, B. H., Lalonde, S., Takanaga, H., Hartung, M. L., Qu, X. Q., Guo, W. J., Kim, J. G., Underwood, W., Chaudhuri, B., Chermak, D., Antony, G., White, F. F., Somerville, S. C., Mudgett, M. B., and Frommer, W. B. 2010. Sugar transporters for intercellular exchange and nutrition of pathogens. Nature 468:527-532.

Cubero, J., and Graham, J. H. 2002. Genetic relationship among worldwide strains of Xanthomonas causing canker in citrus species and design of new primers for their identification by PCR. Appl. Environ. Microbiol. 68: 1257-1264.

Dangl, J. L., Horvath, D. M., and Staskawicz, B. J. 2013. Pivoting the plant immune system from dissection to deployment. Science 341:746-751.

Daurelio, L. D., Romero, M. S., Petrocelli, S., Merelo, P., Cortadi, A. A., Talon, M., Tadeo, F. R., and Orellano, E. G. 2013. Characterization of Citrus sinensis transcription factors closely associated with the non-host response to Xanthomonas campestris pv. vesicatoria. J. Plant Physiol. 170: 934-942.

de Souza, T. A., Soprano, A. S., de Lira, N. P., Quaresma, A. J., Pauletti, B. A., Paes Leme, A. F., and Benedetti, C. E. 2012. The TAL effector PthA4 interacts with nuclear factors involved in RNA-dependent processes including a HMG protein that selectively binds poly(U) RNA. PLoS One 7: e32305.

Doyle, E. L., Booher, N. J., Standage, D. S., Voytas, D. F., Brendel, V. P., Vandyk, J. K., and Bogdanove, A. J. 2012. TAL effector-nucleotide targeter (TALE-NT) 2.0: Tools for TAL effector design and target prediction. Nucleic Acids Res. 40:W117-W122.

Du, Z., Zhou, X., Ling, Y., Zhang, Z., and Su, Z. 2010. agriGO: A GO analysis toolkit for the agricultural community. Nucleic Acids Res. 38:W64-W70.

Duan, Y., Castaneda, A., Zhao, G., Erdos, G., and Gabriel, D. 1999. Expression of a single, host-specific, bacterial pathogenicity gene in plant cells elicits division, enlargement, and cell death. Mol. Plant-Microbe Interact. 12:556-560.

Escalon, A., Javegny, S., Vernière, C., Noël, L. D., Vital, K., Poussier, S., Hajri, A., Boureau, T., Pruvost, O., Arlat, M., and Gagnevin, L. 2013. Variations in type III effector repertoires, pathological phenotypes and host range of Xanthomonas citri pv. citri pathotypes. Mol. Plant Pathol. 14:483-496.

Espinosa, A., and Alfano, J. R. 2004. Disabling surveillance: Bacterial type III secretion system effectors that suppress innate immunity. Cell. Microbiol. 6:1027-1040. 
Fu, X. Z., Gong, X. Q., Zhang, Y. X., Wang, Y., and Liu, J. H. 2012. Different transcriptional response to Xanthomonas citri subsp. citri between kumquat and sweet orange with contrasting canker tolerance. PLoS One 7:e41790.

Fu, X. Z., and Liu, J. H. 2013. Transcriptional profiling of canker-resistant transgenic sweet orange (Citrus sinensis Osbeck) constitutively overexpressing a spermidine synthase gene. BioMed Res. Int. 2013:Article ID 918136. doi:10.1155/2013/918136

Fu, Z. Q., and Dong, X. 2013. Systemic acquired resistance: Turning local infection into global defense. Annu. Rev. Plant Biol. 64:839-863.

Fu, Z. Q., Guo, M., Jeong, B. R., Tian, F., Elthon, T. E., Cerny, R. L., Staiger, D., and Alfano, J. R. 2007. A type III effector ADP-ribosylates RNAbinding proteins and quells plant immunity. Nature 447:284-288.

Grau, J., Wolf, A., Reschke, M., Bonas, U., Posch, S., and Boch, J. 2013. Computational predictions provide insights into the biology of TAL effector target sites. PLoS Comput. Biol. 9:e1002962.

Gu, K., Yang, B., Tian, D., Wu, L., Wang, D., Sreekala, C., Yang, F., Chu, Z., Wang, G. L., White, F. F., and Yin, Z. 2005. R gene expression induced by a type-III effector triggers disease resistance in rice. Nature 435:1122-1125.

Hann, D. R., Gimenez-Ibanez, S., and Rathjen, J. P. 2010. Bacterial virulence effectors and their activities. Curr. Opin. Plant Biol. 13:388-393.

Hotson, A., Chosed, R., Shu, H., Orth, K., and Mudgett, M. B. 2003. Xanthomonas type III effector XopD targets SUMO-conjugated proteins in planta. Mol. Microbiol. 50:377-389.

Hu, Y., Zhang, J., Jia, H., Sosso, D., Li, T., Frommer, W. B., Yang, B., White, F. F., Wang, N., and Jones, J. B. 2014. Lateral organ boundaries 1 is a disease susceptibility gene for citrus bacterial canker disease. Proc. Natl. Acad. Sci. USA 111:E521-E529.

Hwang, I. S., and Hwang, B. K. 2010. Role of the pepper cytochrome P450 gene $\mathrm{CaCYP} 450 \mathrm{~A}$ in defense responses against microbial pathogens. Planta 232:1409-1421.

Jalan, N., Kumar, D., Andrade, M. O., Yu, F., Jones, J. B., Graham, J. H., White, F. F., Setubal, J. C., and Wang, N. 2013. Comparative genomic and transcriptome analyses of pathotypes of Xanthomonas citri subsp. citri provide insights into mechanisms of bacterial virulence and host range. BMC Genomics 14:551.

Janjusevic, R., Abramovitch, R. B., Martin, G. B., and Stebbins, C. E. 2006. A bacterial inhibitor of host programmed cell death defenses is an E3 ubiquitin ligase. Science 311:222-226.

Kay, S., Hahn, S., Marois, E., Hause, G., and Bonas, U. 2007. A bacterial effector acts as a plant transcription factor and induces a cell size regulator. Science 318:648-651.

Khalaf, A., Moore, G. A., Jones, J. B., and Gmitter, F. G., Jr. 2007. New insights into the resistance of Nagami kumquat to canker disease. Physiol. Mol. Plant Pathol. 71:240-250.

Khalaf, A. A., Gmitter, F. G., Jr., Conesa, A., Dopazo, J., and Moore, G. A. 2011. Fortunella margarita transcriptional reprogramming triggered by Xanthomonas citri subsp. citri. BMC Plant Biol. 11:159.

Kim, J. G., Li, X., Roden, J. A., Taylor, K. W., Aakre, C. D., Su, B., Lalonde, S., Kirik, A., Chen, Y., Baranage, G., McLane, H., Martin, G. B., and Mudgett, M. B. 2009. Xanthomonas T3S effector XopN suppresses PAMPtriggered immunity and interacts with a tomato atypical receptor-like kinase and TFT1. Plant Cell 21:1305-1323.

Lahaye, T., and Bonas, U. 2001. Molecular secrets of bacterial type III effector proteins. Trends Plant Sci. 6:479-485.

Laia, M. L., Moreira, L. M., Dezajacomo, J., Brigati, J. B., Ferreira, C. B., Ferro, M. I., Silva, A. C., Ferro, J. A., and Oliveira, J. C. 2009. New genes of Xanthomonas citri subsp. citri involved in pathogenesis and adaptation revealed by a transposon-based mutant library. BMC Microbiol. 9:12.

Langlois-Meurinne, M., Gachon, C. M., and Saindrenan, P. 2005. Pathogenresponsive expression of glycosyltransferase genes UGT73B3 and UGT73B5 is necessary for resistance to Pseudomonas syringae pv. tomato in Arabidopsis. Plant Physiol. 139:1890-1901.

Li, H., Xu, H., Zhou, Y., Zhang, J., Long, C., Li, S., Chen, S., Zhou, J. M., and Shao, F. 2007. The phosphothreonine lyase activity of a bacterial type III effector family. Science 315:1000-1003.

Li, Z., Zou, L., Ye, G., Xiong, L., Ji, Z., Zakria, M., Hong, N., Wang, G., and Chen, G. 2014. A potential disease susceptible gene CsLOB of citrus is targeted by a major virulence effector PthA of Xanthomonas citri subsp. citri. Mol. Plant 7:912-915.

Livak, K. J., and Schmittgen, T. D. 2001. Analysis of relative gene expression data using real-time quantitative PCR and the $2^{-\Delta \Delta C T}$ methods. Methods 25 : 402-408

Marois, E., Van den Ackerveken, G., and Bonas, U. 2002. The Xanthomonas type III effector protein AvrBs3 modulates plant gene expression and induces cell hypertrophy in the susceptible host. Mol. Plant-Microbe Interact. 15:637-646.

Moreira, L. M., Almeida, N. F., Potnis, N., Digiampietri, L. A., Adi, S. S., Bortolossi, J. C., da Silva, A. C., da Silva, A. M., de Moraes, F. E., de Oliveira, J. C., de Souza, R. F., Facincani, A. P., Ferraz, A. L., Ferro, M. I., Furlan, L. R., Gimenez, D. F., Jones, J. B., Kitajima, E. W., Laia, M. L., Leite, R. P., Nishiyama, M. Y., Rodrigues Neto, J., Nociti, L. A., Norman, D. J., Ostroski, E. H., Pereira, H. A., Staskawicz, B. J., Tezza, R. I., Ferro, J. A., Vinatzer, B. A., and Setubal, J. C. 2010. Novel insights into the genomic basis of citrus canker based on the genome sequences of two strains of Xanthomonas fuscans subsp. aurantifolii. BMC Genomics 11: 238.

Moscou, M. J., and Bogdanove, A. J. 2009. A simple cipher governs DNA recognition by TAL effectors. Science 326:1501.

Pérez-Quintero, A. L., Rodriguez-R, L. M., Dereeper, A., López, C., Koebnik, R., Szurek, B., and Cunnac, S. 2013. An improved method for TAL effectors DNA-binding sites prediction reveals functional convergence in TAL repertoires of Xanthomonas oryzae strains. PLoS One 8:e68464.

Schaad, N. W., Postnikova, E., Lacy, G., Sechler, A., Agarkova, I., Stromberg, P. E., Stromberg, V. K., and Vidaver, A. K. 2006. Emended classification of xanthomonad pathogens on citrus. Syst. Appl. Microbiol. 29:690-695.

Sels, J., Mathys, J., De Coninck, B. M., Cammue, B. P., and De Bolle, M. F. 2008. Plant pathogenesis-related (PR) proteins: A focus on PR peptides. Plant Physiol. Biochem. 46:941-950.

Shao, F., Golstein, C., Ade, J., Stoutemyer, M., Dixon, J. E., and Innes, R. W. 2003. Cleavage of Arabidopsis PBS1 by a bacterial type III effector. Science 301:1230-1233.

Swarup, S., Yang, Y., Kingsley, M. T., and Gabriel, D. W. 1992. An Xanthomonas citri pathogenicity gene, pthA, pleiotropically encodes gratuitous avirulence on nonhosts. Mol. Plant-Microbe Interact. 5:204-213.

Tasset, C., Bernoux, M., Jauneau, A., Pouzet, C., Briere, C., Kieffer-Jacquinod, S., Rivas, S., Marco, Y., and Deslandes, L. 2010. Autoacetylation of the Ralstonia solanacearum effector PopP2 targets a lysine residue essential for RRS1-R-mediated immunity in Arabidopsis. PLoS Pathog. 6:e1001202.

Thimm, O., Blasing, O., Gibon, Y., Nagel, A., Meyer, S., Kruger, P., Selbig, J., Muller, L. A., Rhee, S. Y., and Stitt, M. 2004. MAPMAN: A user-driven tool to display genomics data sets onto diagrams of metabolic pathways and other biological processes. Plant J. 37:914-939.

Truman, W., de Zabala, M. T., and Grant, M. 2006. Type III effectors orchestrate a complex interplay between transcriptional networks to modify basal defence responses during pathogenesis and resistance. Plant J. 46: 14-33.

Usadel, B., Nagel, A., Thimm, O., Redestig, H., Blaesing, O. E., Palacios-Rojas, N., Selbig, J., Hannemann, J., Piques, M. C., Steinhauser, D., Scheible, W. R., Gibon, Y., Morcuende, R., Weicht, D., Meyer, S., and Stitt, M. 2005. Extension of the visualization tool MapMan to allow statistical analysis of arrays, display of corresponding genes, and comparison with known responses. Plant Physiol. 138:1195-1204.

Vogt, T., and Jones, P. 2000. Glycosyltransferases in plant natural product synthesis: Characterization of a supergene family. Trends Plant Sci. 5:380386.

Xu, Q., Chen, L. L., Ruan, X., Chen, D., Zhu, A., Chen, C., Bertrand, D., Jiao, W. B., Hao, B. H., Lyon, M. P., Chen, J., Gao, S., Xing, F., Lan, H., Chang, J. W., Ge, X., Lei, Y., Hu, Q., Miao, Y., Wang, L., Xiao, S., Biswas, M. K., Zeng, W., Guo, F., Cao, H., Yang, X., Xu, X. W., Cheng, Y. J., Xu, J., Liu, J. H., Luo, O. J., Tang, Z., Guo, W. W., Kuang, H., Zhang, H. Y., Roose, M. L., Nagarajan, N., Deng, X. X., and Ruan, Y. 2013. The draft genome of sweet orange (Citrus sinensis). Nat. Genet. 45:59-66.

Yan, Q., and Wang, N. 2012. High-throughput screening and analysis of genes of Xanthomonas citri subsp. citri involved in citrus canker symptom development. Mol. Plant-Microbe Interact. 25:69-84.

Yang, B., Sugio, A., and White, F. F. 2006. Os8N3 is a host diseasesusceptibility gene for bacterial blight of rice. Proc. Natl. Acad. Sci. USA 103:10503-10508.

Yu, Y., Streubel, J., Balzergue, S., Champion, A., Boch, J., Koebnik, R., Feng, J., Verdier, V., and Szurek, B. 2011. Colonization of rice leaf blades by an African strain of Xanthomonas oryzae pv. oryzae depends on a new TAL effector that induces the rice nodulin-3 Os11N3 gene. Mol. Plant-Microbe Interact. 24:1102-1113.

Zheng, L., Lifang, Z., Gang, Y., Li, X., Zhiyuan, J., Muhammad, Z., Ni, H., Guoping, W., and Gongyou, C. 2014. A potential disease susceptible gene $C S L O B$ of citrus is targeted by a major virulence effector PthA of Xanthomonas citri subsp. citri. Mol. Plant 7:912-915. 